\title{
Effects of Novel Environmental Stimuli on Neuroendocrine Activity in Thoroughbred Horses
}

\author{
Tetsuro HADA ${ }^{1 *}$, Tatsushi ONAKA ${ }^{2}$, Ryo KUSUNOSE ${ }^{1}$ and Kinji YAGI ${ }^{2}$ \\ ${ }^{1}$ Equine Research Institute, Japan Racing Association, 321-4 Tokami-cho, Utsunomiya, Tochigi 320-0856 and \\ ${ }^{2}$ Department of Physiology, Jichi Medical School, 3311 Yakushiji, Minamikawachi-machi, Kawachi-gun, Tochigi \\ 329-0498, Japan
}

Emotional stimuli have been shown to suppress vasopressin and facilitate oxytocin release from the posterior pituitary in some mammalian species. However, it is not clear in horses. Here we examined effects of novel environmental stimuli on plasma concentrations of vasopressin, oxytocin, cortisol, adrenaline and noradrenaline in Thoroughbred horses. To impose novel environmental stimuli, horses were introduced to an experimental stall $(4.5 \times$ $5.0 \mathrm{~m}$ ) with side walls of black rubber board, in which a yellow balloon ( $80 \mathrm{~cm}$ in diameter) was hung from the ceiling. Horses were exposed to the novel environmental stimuli for 3 min. Heart rates were significantly increased during the stimuli. Plasma concentrations of adrenaline and noradrenaline in the blood collected immediately after the stimuli were twice as high as those at rest and decreased to the basal levels within 10 min after the stimuli. Plasma cortisol concentration increased after the stimuli and reached the peak 20 min later. However, plasma concentrations of vasopressin and oxytocin did not significantly change throughout the experiments. These data suggest that the novel environmental stimuli do not significantly influence the hypothalamo-neurohypophysial system while the stimuli activate the sympatho-adrenal medulla and the hypothalamo-pituitary-adrenal cortical axes in horses.

Key words: novel environment, oxytocin, stress, vasopressin
J. Equine Sci. Vol. 12, No. 2

pp. 33-38, 2001
Emotional stimuli have been shown to activate sympatho-adrenomedullary and pituitaryadrenocortical responses in mammalian species including horses [10, 28]. Emotional stimuli such as isolation of a horse from the herd, exposure to a novel environment or confinement of a horse with dominant residents facilitate ACTH, cortisol, adrenaline or noradrenaline release $[3,4,14]$.

On the other hand, vasopressin release from the posterior pituitary has been shown to be suppressed by emotional stimuli in some mammalian species [41]. For example, conditioned fear or novel environmental stimuli have been shown to inhibit vasopressin release from the posterior pituitary in rats [23-27]. In sheep, isolation of an animal from the herd has been also shown to inhibit the vasopressin release [29]. In

This article was accepted June 15, 2001.

*Corresponding author. e-mail: hada@center.equinst.go.jp horses, however, isolation stress has been reported to increase vasopressin concentrations in the pituitary venous blood [3], indicating that vasopressin release is increased from the median eminence and/or the posterior pituitary by emotional stimuli in horses. It is thus possible that control of vasopressin release after emotional stimuli in horses may be different from that in other mammalian species.

In the case of oxytocin, emotional stimuli have been shown to facilitate oxytocin release from the posterior pituitary in rats [23, 27] in human [38]. In horses, on the other hand, effects of emotional stimuli upon oxytocin concentrations in the peripheral blood have not been reported.

The present experiments aimed to discover the effects of novel environmental stimuli on release of arginine vasopressin and oxytocin from the posterior pituitary in horses. We measured vasopressin and oxytocin concentrations in the peripheral blood of 
male Thoroughbred horses before and after novel environmental stimuli. We also measured heart rates and plasma concentrations of cortisol, adrenaline and noradrenaline, since these parameters are known as physiological indexes of acute stress.

\section{Materials and Methods}

Horses

Eight healthy male Thoroughbred horses were used $(24.8 \pm 0.4$ months old $)$.

\section{Novel environmental stimuli}

The tests were performed between 13:00 and 14:30. An experimental stall $(4.5 \times 5.0 \mathrm{~m})$, in which side walls are made of black rubber board, was used. In the experimental stall, a yellow balloon was hung from the ceiling above the horse's back. The stall was about $50 \mathrm{~m}$ apart from their home stalls and the horses had never been in it before. The horses were taken into the experimental stall, kept there for $3 \mathrm{~min}$ and brought back in their individual home stalls.

\section{Blood sampling}

A catheter (14 G, Angiocath, Beckon Dickinson, Sandy, USA) was placed in the left jugular vein at least 90 min before the first blood sampling. Bloods of horses during the experiment were collected via the catheter at rest, immediately before and after the stimuli and 5, 10, 20, 30, 60 and 120 min after the stimuli. The blood samples were immediately put into tubes containing disodium ethylene diamine tetraacetic acid $(7.5 \mathrm{mg} / 5 \mathrm{ml})$ and kept in ice. Each plasma sample was separated by centrifuge and kept at $-80^{\circ} \mathrm{C}$ until measurements of hormones.

\section{Measurements}

A heart rate monitor (VANTAGE XL, POLAR, Kempele, Finland) was attached to the chests of the horses and their heart rates were recorded at a 5-sec interval.

Plasma concentrations of cortisol were measured by radioimmunoassay (RIA) with a specific anti-serum against cortisol (\#A907/R1Y, Biogenesis, Poole, England) as described previously [5]. The intra- and inter-assay coefficient of variance was 5 and $9 \%$. Plasma concentrations of adrenaline and noradrenaline were measured by a high-performance liquid

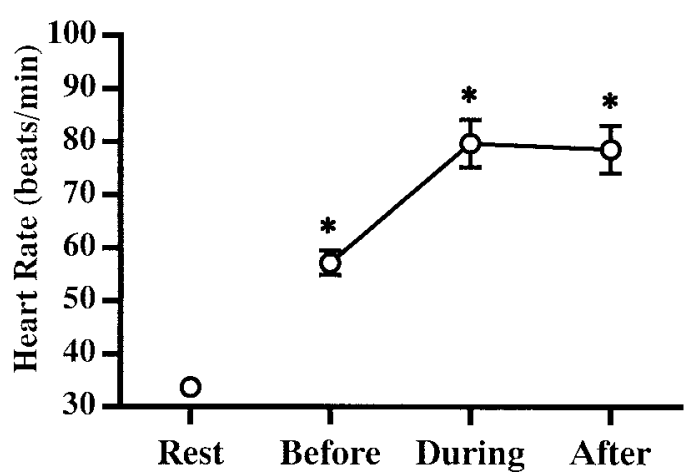

Fig. 1. Mean heart rates before, during and after the novel environmental stimuli. Data indicate mean \pm S.E.M. for $1 \mathrm{~min}$ at rest and for $3 \mathrm{~min}$ before, during and after the novel environmental stimuli. *: $\mathrm{p}<0.05$ VS the values at rest (Rest) by Fisher's PLSD analysis.

chromatography (C-RA, Shimadzu, Tokyo, Japan) with an electrochemical detector (Nanospace SI-1, Shiseido, Tokyo, Japan) as described previously [18]. The intraand inter-assay coefficient of variance for adrenaline and noradrenaline was $2 \%$, respectively. Plasma samples were extracted with acetone and diethyl ether for vasopressin measurements. Vasopressin concentrations were measured by RIA with a specific anti-serum [36] as described previously [26]. Plasma concentrations of oxytocin were measured by RIA as described [24]. The intra- and inter-assay coefficient of variance was $6 \%$ and $14 \%$ for vasopressin, and $4 \%$ and $10 \%$ for oxytocin RIA.

Plasma osmolality was measured by a freezing point depression method with an osmometer (Fiske one-ten, Fiske, Norwood, USA).

\section{Statistics}

Data were expressed as mean \pm S.E.M. For statistical analysis, two-way ANOVA and Fisher's PLSD analysis were employed.

\section{Results}

When the horse was brought to the experimental stall, heart rates were significantly higher than those at rest (Fig. 1). The data indicate that the horses were in an excited state before entering the stall (a novel environment). When the horses were introduced into the experimental stall, they showed restless movements, 
A)

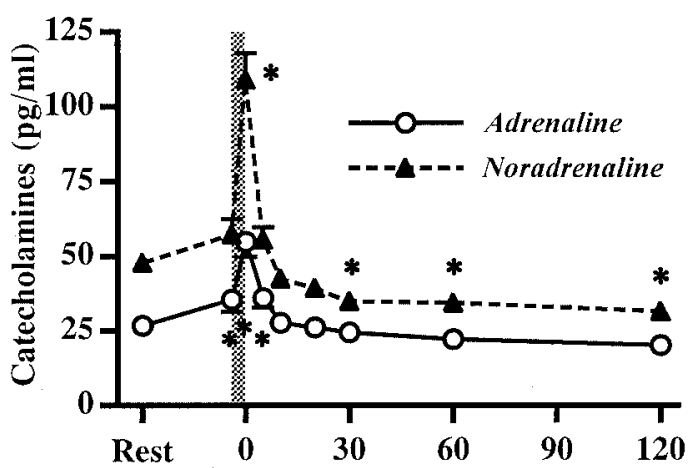

B)

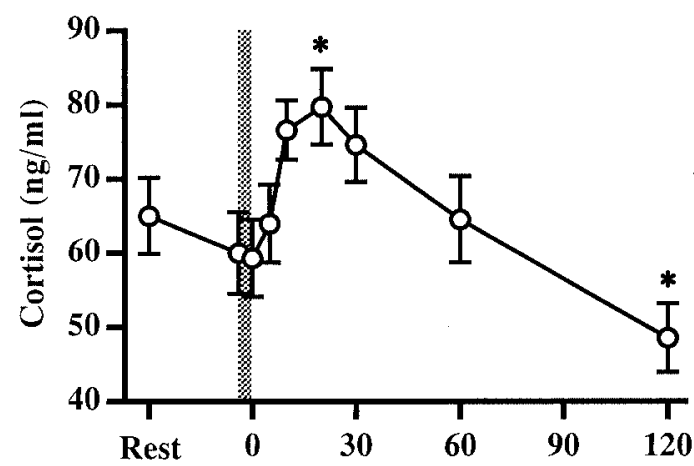

C)

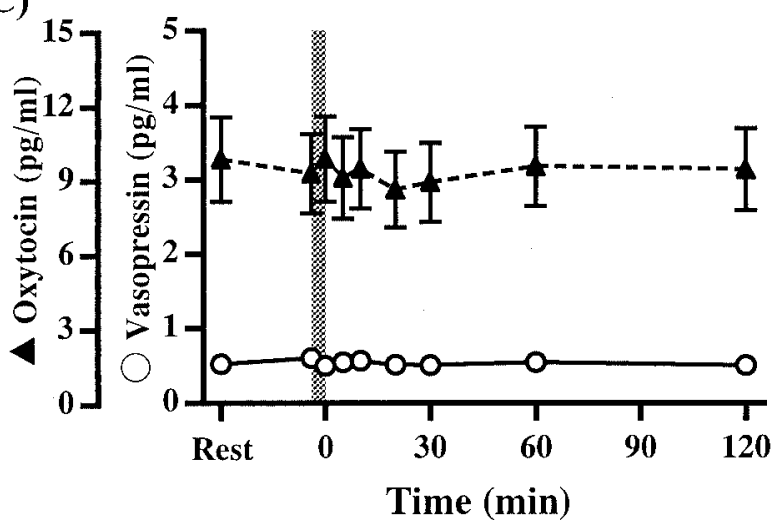

Fig. 2. Plasma concentrations of A) adrenaline, noradrenaline, B) cortisol, C) vasopressin and oxytocin before, during and after the novel environmental stimuli. Hatched boxes indicate the period of the novel environmental stimuli. *: p<0.05 VS the values at rest (Rest) by Fisher's PLSD analysis.

neighing and hyperventilating. Heart rates were further increased in the stall and remained at the high level.

Plasma concentrations of adrenaline and noradrenaline immediately after the novel

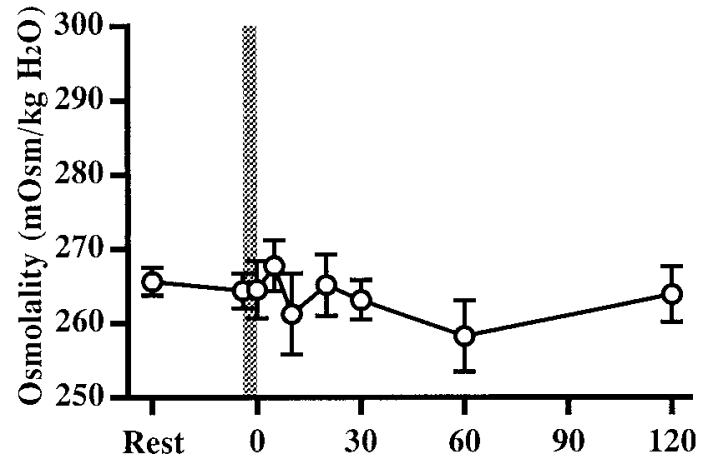

Fig. 3. Plasma osmolality before, during and after the novel environmental stimuli. A hatched box indicates the period of the novel environmental stimuli.

environmental stimuli increased twice as high as those at rest and returned to the basal levels within $10 \mathrm{~min}$ after the stimuli (Fig. 2-A).

Plasma concentration of cortisol began to increase after the stimuli and reached the peak 20 min later (Fig. 2-B). Then it decreased gradually and returned to the basal level within $60 \mathrm{~min}$ after the stimuli and further went down to a sub-basal level.

Plasma concentrations of vasopressin and oxytocin were not significantly changed throughout the experiments (Fig. 2-C). We also measured plasma osmolality, since vasopressin release from the posterior pituitary depends upon body fluid osmolality [31]. Plasma osmolality was not significantly changed (Fig. 3).

\section{Discussion}

A variety of stressful stimuli have been shown to facilitate releases of ACTH, cortisol, adrenaline and noradrenaline in mammalian species $[10,28]$ including horses $[2-4,6,7,12,13,15-19,22,37,39$, 40]. In the present study, exposure of horses to the novel environmental stimuli increased heart rates and plasma concentrations of cortisol, adrenaline and noradrenaline. These data, therefore, indicate that the environmental stimuli exited the horses emotionally. However, the stimuli did not significantly change plasma concentrations of vasopressin or oxytocin. Thus the results suggest that novel environmental stimuli do not significantly change release of vasopressin and oxytocin in horses. Consistent with this idea, it has been shown that isolation of a horse from 
the herd does not change plasma vasopressin concentrations in the jugular venous blood [3].

On the other hand, isolation stress in horses has been shown to increase vasopressin concentration in the pituitary venous blood [3]. The apparent discrepancies in vasopressin data between the jugular and pituitary venous blood may be related to the fact that vasopressin is released both from the median eminence and the posterior pituitary. While vasopressin concentrations in the pituitary venous blood reflect the sum of vasopressin released from the median eminence and the pituitary, those in the peripheral blood are considered to mainly reflect the amount released from the posterior pituitary, since neurohypophysectomy has been shown to induce severe diabetes insipidus, a symptom of vasopressin deficiency in the peripheral plasma [11], and to almost completely abolish an increase of vasopressin after hypotension [30]. Vasopressin release from the median eminence has been shown to increase after emotional stress in rats $[8,32,33]$. It is thus possible that emotional stimuli facilitate vasopressin release from the median eminence but not from the posterior pituitary. Another possibility, however, is not excluded that novel environmental stimuli in the present study or isolation stress in the previous study [3] were not sufficiently strong for inducing a significant change in vasopressin release from the posterior pituitary in horses.

Plasma vasopressin concentration in the peripheral blood has been shown to decrease after emotional stimuli in rats [23-27] and sheep [29]. These results contradict the present data in horses. Causes of this discrepancy are unclear at present. However, two explanations are possible. One may be the difference in experimental designs (osmotic conditions of the body fluid and emotional stimuli used), and the other may be the existence of species difference. Vasopressin plays an important role in maintaining blood volume and blood pressure, and increasing blood flow in muscles [21]. So that, it is tempting to speculate that keeping plasma vasopressin concentrations high and, as a result, maintaining sufficient blood flow in the muscles during emotional stress may have a survival value in horses, since large-sized animals such as horses ought to flee rather than stay still and hide themselves when they come across their predators. In this context, it has been demonstrated in horses that the physical exercise facilitates vasopressin release from the posterior pituitary [2, 20].
The present study demonstrated, for the first time, in horses that novel environmental stimuli do not significantly change plasma oxytocin concentrations in the peripheral blood. In rats, oxytocin concentration in the peripheral blood has been shown to increase [27, 42] or unchanged [9, 15, 25] after novel environmental stimuli. It is of interest to note the study showing that emotional stimuli facilitate oxytocin release from the median eminence in rats $[33,34]$. In horses, isolation stress has been claimed to increase oxytocin concentrations in the pituitary blood of horses [1]. The data appear to suggest that emotional stimuli facilitate release of oxytocin as well as vasopressin from the median eminence. Oxytocin released from the median eminence may contribute to ACTH release from the pituitary in horses, as suggested in rodents [35].

In conclusion, we found that novel environmental stimuli do not significantly change vasopressin and oxytocin release from the posterior pituitary in horses, although the stimuli facilitated release of cortisol, adrenaline and noradrenaline. Thus, it is suggested that in horses unlike in rodents or the other mammalian species studied previously, vasopressin release from the posterior pituitary is not suppressed after emotional stimuli. The present study, however, does not assess vasopressin release from the median eminence. Measurements of hormone concentrations in the pituitary venous blood as well as in the peripheral blood remains to be taken for clarification of vasopressin release from the median eminence and from the posterior pituitary.

\section{Acknowledgments}

This study was supported by a grant-in-aid from the Equine Research Institute, Japan Racing Association, and from the Ministry of Education, Science, Sports, and Culture, Japan. We thank Dr. Y. Nambo and Dr. F. Sato (JRA Equine Research Institute) for technical assistance, Miss A. Yoshida (Department of Physiology, Jichi Medical School) for measuring plasma osmolality and plasma concentrations of vasopressin and oxytocin, and Dr. M. Kurosawa, Dr. S. Nagata and Mrs. F. Takeda (Laboratory of Racing Chemistry) for measuring plasma concentrations of adrenaline and noradrenaline. We are also grateful to Dr. Ohno (Mitsubishi Yuka) and Prof Higuchi (Fukui Medical School) for their generous gifts of specific antivasopressin and anti-oxytocin serum. 


\section{References}

1. Alexander, S.L., Irvine, C.H.G., and Donald, R.A. 1996. Dynamics of the regulation of the hypothalamo-pituitary-adrenal (HPA) axis determined using a nonsurgical method for collecting pituitary venous blood from horses. Front. Neuroendocrinol. 17: 1-50.

2. Alexander, S.L., Irvine, C.H.G., Ellis, M.J., and Donald, R.A. 1991. The effect of acute exercise on the secretion of corticotropin-releasing factor, arginine vasopressin, and adrenocorticotropin as measured in pituitary venous blood from the horse. Endocrinology 128: 65-72.

3. Alexander, S.L., Irvine, C.H.G., Livesey, J.H., and Donald, R.A. 1988. Effect of isolation stress on concentrations of arginine vasopressin, $\alpha$ melanocyte-stimulating hormone and ACTH in the pituitary venous effuent of the normal horse. $J$. Endocrinol. 116: 325-334.

4. Alexander, S.L. and Irvine, C.H.G. 1998. The effect of social stress on adrenal axis activity in horses: the importance of monitoring corticosteroid-binding globulin capacity. $J$. Endocrinol. 157: 425-432.

5. Arai, K., Watanabe, G., Fujimoto, M., Nagata, S., Takemura, Y., Taya, K., and Sasamoto, S. 1995. A sensitive radioimmunoassay for cortisol using 125I-labeled radioligand. J. Reprod. Develop. 41: 1520 (in Japanese with English summary).

6. Church, D.B., Evans, D.L., Lewis, D.R., and Rose, R.J. 1987. The effect of exercise on plasma adrenocorticotrophin, cortisol and insulin in the horse and adaptations with training. Equine Exercise Physiology 2: 506-515.

7. Colborn, D.R., Thompson, Jr. D.L., Roth, T.L., Capehart, J.S., and White, K.L. 1991. Responses of cortisol and prolactin to sexual excitement and stress in stallions and geldings. J. Anim. Sci. 69: 2556-2562.

8. De Goeij, D.C., Dijkstra, H., and Tilders, F.J. 1992. Chronic psychosocial stress enhances vasopressin, but not corticotropin-releasing factor, in the external zone of the median eminence of male rats: relationship to subordinate status. Endocrinology 131: 847-853.

9. Dohanics, J., Hoffman, G.E., and Verbalis, J.G. 1991. Hyponatremia-induced inhibition of magnocellular neurons causes stressor-selective impairment of stimulated adrenocorticotropin secretion in rats. Endocrinology 128: 331-340.

10. Hart B.B., Stanford, G.G., Ziegler, M.G., Lake,
C.R., and Chernow, B. 1989. Catecholamines: study of interspecies variation. Crit. Care. Med. 17: 1203-1222.

11. Herman, J.P., Marciano, F.F., Wiegand, S.J., and Gash, D.M. 1987. Selective cell death of magnocellular vasopressin neurons in neurohypophysectomized rats following chronic administration of vasopressin. J. Neurosci. 7: 25642575.

12. Hydbring, E., Nyman, S., and Dahlborn, K. 1996. Changes in plasma cortisol, plasma $\beta$ endorphin, heart rate, haematocrit and plasma protein concentration in horses during restraint and use of a naso-gastric tube. Pferdeheilkunde 12: 423-427.

13. Irvine, C.H. and Alexander, S.L. 1994. Factors affecting the circadian rhythm in plasma cortisol concentrations in the horse. Domest. Anim. Endocrinol. 11: 227-238.

14. Irvine, C.H.G., Alexander, S.L., and Donald, R.A. 1989. Effect of an osmotic stimulus on the secretion of arginine vasopressin and adrenocorticotropin in the horse. Endocrinology 124: 3102-3108.

15. Ivanyi, T., Wiegant, V.M., and de Wied, D. 1991. Differential effects of emotional and physical stress on the central and peripheral secretion of neurohypophysial hormones in male rats. Life Sci. 48: 1309-1316.

16. Jimenez, H., Hinchcliff, K.W., and Farris, J.W. 1998. Catecholamine and cortisol responses of horses to incremental exertion. Vet. Res. Commun. 22: 107-118.

17. Kurosawa, M., Nagata, S., Takeda, F., Mima, K., Hiraga, A., Kai, M., and Taya, K. 1998. Plasma catecholamine, adrenocorticotropin and cortisol responses to exhaustive incremental treadmill exercise of the thoroughbred horse. J. Equine Sci. 9: 9-18.

18. Kurosawa, M., Takeda, F., Nagata, S., and Mima, K. 1997. Circadian variations in plasma adrenaline and noradrenaline in the thoroughbred horse. $J$. Equine Sci. 8: 81-88.

19. Linden, A., Art, T., Amory, H., Desmecht, D., and Lekeux, P. 1987. Effect of 5 different types of exercise, transportation and ACTH administration on plasma cortisol concentration in sport horses. Equine Exercise Physiology 3: 391396.

20. McKeever, K.H., Hinchcliff, K.W., Schmall, L.M., Reed, S.M., Lamb, D.R., and Muir III, W.W. 1992. Plasma renin activity and aldosterone and vasopressin concentrations during incremental 
treadmill exercise in horses. Am. J. Vet. Res. 53: 1290-1293.

21. Michelini, L.C. and Morris, M. 1999. Endogenous vasopressin modulates the cardiovascular responses to exercise. Ann. N.Y. Acad. Sci. 897: 198-211.

22. Nagata, S., Takeda, F., Kurosawa, M., Mima, K., Hiraga, A., Kai, M., and Taya, K. 1999. Plasma adrenocorticotropin, cortisol, Catecholamines response to various exercises. Equine vet. J. Suppl. 30: $570-574$.

23. Onaka, T. 2000. Catecholaminergic mechanisms underlying neurohypophysial hormone responses to unconditioned or conditioned aversive stimuli in rats. Exp. Physiol. 85S: 101S-110S.

24. Onaka, T. and Yagi, K. 1990. Differential effects of naloxone on neuroendocrine responses to fearrelated emotional stress. Exp. Brain Res. 81: 53-58.

25. Onaka, T. and Yagi, K. 1993. Effects of novelty stress on vasopressin and oxytocin secretion by the pituitary in the rat. J. Neuroendocrinol. 5: 365-369.

26. Onaka, T., Yagi, K., and Hamamura, M. 1988. Vasopressin secretion: suppression after light and tone stimuli previously paired with footshocks in rats. Exp. Brain Res. 71: 291-297.

27. Onaka, T. and Yagi, K. 1997. Neural mechanisms underlying neuroendocrine responses to emotional stress. Shinkei Kenkyuu no Shinpo 41: 563-573 (in Japanese with English summary).

28. Ottaviani, E., Franchini, A., and Genedani, S. 1999. ACTH and its role in immunoneuroendocrine function. A comparative study. Curr. Pharm. Des. 5: 673-681.

29. Parrott, R.F., Thornton, S.N., and Robinson, J.E. 1988. Endocrine responses to acute stress in castrated rams: no increase in oxytocin but evidence for an inverse relationship between cortisol and vasopressin. Acta Endocrinologica (Copenh.) 117: 381-386.

30. Raff, H., Merrill, D.C., Skelton, M.M., Brownfield, M.S., and Cowley, A.W. Jr. 1988. Control of adrenocorticotropin secretion and adrenocortical sensitivity in neurohypophysectomized conscious dogs: effects of acute and chronic vasopressin replacement. Endocrinology 122: 1410-1418.

31. Robertson, G.L., Shelton, R.L., and Athar, S. 1976. The osmoregulation of vasopressin. Kidney
International 10: 25-37.

32. Romero, L.M., Levine, S., and Sapolsky, R.M. 1995. Adrenocorticotropin secretagog release: stimulation by frustration and paradoxically by reward presentation. Brain Res. 676: 151-156.

33. Romero, L.M., Levine, S., and Sapolsky, R.M. 1995. Patterns of adrenocorticotropin secretagog release in response to social interactions and various degrees of novelty. Psychoneuroendocrinology 20: 183-191.

34. Romero, L.M., Plotsky, P.M., and Sapolsky, R.M. 1993. Patterns of adrenocorticotropin secretagog release with hypoglycemia, novelty, and restraint after colchicine blockade of axonal transport. Endocrinology 132: 199-204.

35. Romero, L.M. and Sapolosky, R.M. 1996. Patterns of ACTH secretagog secretion in response to psychological stimuli. J. Neuroendocrinol. 8: 243258.

36. Sakurai, H., Kurimoto, F., Ohono, H., Kanai, A., Nomura, K., Demura, H., and Shizume, K. 1985. A simple and highly sensitive radioimmunoassay for 8-arginine vasopressin in human plasma using a reversed-phase C18 silica column. Nippon Naibunpi Gakkai Zasshi 61: 724-736 (in Japanese with English summary).

37. Snow, D.H., Harris, R.C., Macdonald, I.A., Forster, C.D., and Marlin, D.J. 1992. Effects of highintensity exercise on plasma catecholamines in the thoroughbred horse. Equine vet. J. 24: 462-467.

38. Sanders, G., Freilicher. J., and Lightman, S.L. 1990. Psychological stress of exposure to uncontrollable noise increases plasma oxytocin in high emotionality women. Psychoneuroendocrinology 15: 47-58.

39. Stull, C.L. 1999. Responses of horses to trailer design, duration, and floor area during commercial transportation to slaughter. J. Anim. Sci. 77: 2925-2933.

40. Taylor, P.M. 1989. Equine stress responses to anaesthesia. Br. J. Anaesth. 63: 702-709.

41. Yagi, K. 1992. Suppressive vasopressin response to emotional stress. Jpn. J. Physiol. 42: 681-703.

42. Yagi, K. 1994. Effects of a histamine H2-receptor antagonist, ranitidine on the vasopressin and oxytocin responses to novelty stress in the rat. Neurosci. Res. 19: 357-364. 